\title{
ABIOTIC AND ANTHROPOGENIC FACTORS AFFECTING THE DISTRIBUTION OF FOUR SYMPATRIC LARGE HERBIVORES IN THE MOLE NATIONAL PARK, GHANA
}

\author{
K. B. DAKWA \\ Department of Conservation Biology and Entomology, School of Biological Sciences, \\ University of Cape Coast, Ghana \\ Email:dakb92@yahoo.com/kdakwa@ucc.edu.gh
}

\begin{abstract}
The impact of abiotic and anthropogenic factors on the distributions of buffalo (Syncerus caffer), hartebeest (Alcelaphus buselaphus), roan antelope (Hippotragus equinus) and waterbuck (Kobus defassa) at Mole National Park was assessed by transect survey. Generalized linear mixed effects logistic regression was used to model mammal presence/absence as a function of ecological factors. Hartebeest inhabited highlands and avoided floodplains but buffalo and roan avoided floodplains by selecting both lowlands and highlands while waterbuck inhabited lowlands but not necessarily the floodplains. Fire, water availability and anthropogenic activities were limiting factors, which constrained habitat use to make some areas unexplored for foraging. Buffalo, roan and hartebeest did not inhabit areas close to the park's boundaries. Herbivores need optimal environment almost free of constraints to construct their distribution patterns. Therefore, management should address the problems identified in this study to ensure the herbivores' redistribution to maximise their use of resources for their effective conservation.
\end{abstract}

\section{Introduction}

Mole National Park (MNP) was established in 1958 for the protection and conservation of representative savanna fauna in the northern part of Ghana. Though the herbivorous mammals form the majority of the mammalian species richness of the reserve, no previous survey has specifically assessed the ecology of these herbivores. Wildlife research in and around MNP is scanty in general including evaluation of population trends and status of lions (Burton et al., 2010), censuses (Wilson et al., 1993), cost of raids caused by wildlife (Dakwa, 2016a), allometry in sympatric grazers (Dakwa, 2016b), and evaluation of disturbances to water birds (Aikins et al., 2018) and few studies on community and wildlife conflict issues, which remain unpublished. Without research data on distribution of wildlife in a reserve, conservation planning will remain inefficient and ineffective (Bauer et al., 2010). If we are to manage landscapes to conserve wildlife, it is important that we understand the role of landscape factors in determining their distributions. Thus, predicting the distribution of wildlife populations is an important component of the development of management strategies for their conservation.

The aim of this study was to provide research data for the effective conservation of some large herbivores at MNP, specifically to: 1) determine the effect of abiotic (water and altitude) and anthropogenic factors on the distribution of four sympatric large herbivores of MNP, namely, buffalo (Syncerus caffer), roan antelope (Hippotragus equinus), waterbuck 
(Kobus defassa) and hartebeest (Alcelaphus buselaphus) and 2) investigate possible constraints resulting from the influence of those factors in the herbivores' distribution. The results of this study are expected to inform management decisions on effective strategies aimed at the redistribution of these mammals in order to maximise the use of resources at MNP. Knowledge of the distribution of these charismatic mammals at MNP will also boost tourism as this will be integrated into management planning and implementation strategies for effective tour guiding.

\section{Experimental}

Study Area

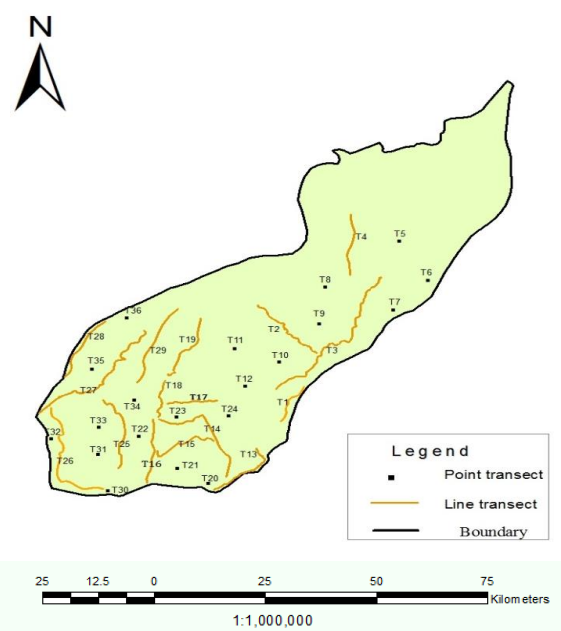

Fig. 1: Study area showing locations of transects identified by numbers.

The Mole National Park (Fig. 1) covers an area of about $4,840 \mathrm{~km} 2$ as Ghana's largest wildlife refuge. The Park is located in northwest Ghana on grassland savanna and riparian ecosystems. This area of Ghana receives an average of $1,100 \mathrm{~mm}$ per year of rainfall; the mean annual temperature of $28^{\circ} \mathrm{C}$ varies from $26^{\circ} \mathrm{C}$ in December to $31^{\circ} \mathrm{C}$ in March; and rela- tive humidity in the rainy season reaches $90 \%$ at night and $70 \%$ day time but the figures drop to $50 \%$ and $20 \%$ respectively in the dry season (Wildlife Division, 2011). The main habitat types in MNP are the Burkea-Terminalia open savanna woodland with Vitellaria paradoxa (BTV), the Burkea-Terminalia savanna woodland with Detarium microcarpum (BTD), the Anogeissus with Vitellaria paradoxa (A), the boval vegetation (Loudetiopsis kerstingii-Polycarpaea tenuifolia community on rocky substrates, riverine forest $(\mathrm{R})$ along most of the rivers in the park, and swamp (S) (Schmitt \& Adu-Nsiah, 1993). The Park is home to over 93 mammal species including the savanna elephant (Loxodonta africana), hippopotamus (Hippopotamus amphibious), buffalo (Syncerus caffer), Defassa waterbuck (Kobus defassa), roan (Hippotragus equinus), and hartebeest (Alcelaphus bucelaphus).

\section{Data Collection}

Sixteen strip transects $200 \mathrm{~m}$ wide, $100 \mathrm{~m}$ either side of the central line and of varying lengths, along existing roads and paths traversing the main habitat types and 20 point transects, measuring $500 \times 500 \mathrm{~m}$ each were used to survey the large herbivores. The transects were at least $1 \mathrm{~km}$ apart and were distributed to ensure as much spatial representation as possible in the study area and their locations were then mapped by a GPS (all Garmin Ltd., Olathe, KA, USA). Presence/absence data on buffalo, roan antelope, waterbuck and hartebeest were collected by walking point transects or driving strip transects at a speed of $20 \mathrm{~km} / \mathrm{h}$ between 07.30-10.30 GMT and 16.00-18.00 GMT, when herbivores are active, at least twice each season (Table 1) between September 2013 and August 2014. Mammals were viewed within the transects with the help of binoculars when it was necessary. 
TABLE 1

Different Seasons at Mole National Park.

\begin{tabular}{lll}
\hline Season & \multicolumn{1}{c}{ Description } & Period \\
\hline Dry & Harmattan with low humidity & October - December \\
Fire & Dry harmattan with low humidity; windy & January - April \\
Rainy & Heavy rains with lightning and thunder & May - July \\
Flood & Slight rains; Lowlands are flooded. & August - September \\
\hline
\end{tabular}

\section{Measurement of abiotic factors}

The most important abiotic factors are thought to be water availability and altitude (Bailey et al., 1996; Groom \& Harris, 2010). Distances of transect habitat and mammal locations from the nearest sources of water were calculated by using the nearest-features extension in ArcGIS (v9.3), after waypoint data stored in GPSs were exported into an ArcGIS (v9.3) environment. Altitudes of transect habitats and mammal locations were recorded by GPSs and the data transferred to a computer. For small habitats along transects, information on the transect habitat location such as distance from the nearest source of water and altitude were assumed to be the same for their mammal locations. However, because broad habitats occupied wide distance variations, such information were taken at the location of each mammal.

\section{Measurement of anthropogenic factors}

Human activities in and around PAs may affect species distribution. In this study, the park's boundary, communities and farms represented possible human presence or activities. Therefore, the distributions of mammals in relation to the locations of the boundaries, communities or farms were investigated by taking GPS readings of the mammals or their habitat locations and calculating their distances from the boundaries, farms or communities by using the nearest-features extension in ArcGIS (v9.3) after waypoint data stored in GPSs were exported into an ArcGIS (v9.3) environment.

\section{Data analysis}

All data were entered into Microsoft Excel tables (version 2013), before being exported into $\mathrm{R}$ statistical software package version 3.1.2 ( $\mathrm{R}$ core team, 2014).

\section{Generalised linear model (GLM)}

The aim of the implementation of the GLM was to model mammal presence/absence (response variable) as a function of abiotic and anthropogenic parameters recorded (explanatory variables), namely: (i) nearest distance from a source of water (ii) altitude (iii) nearest distance from the park's boundary, and (iv) nearest distance from a community or farm. The idea behind this analysis was to investigate how these factors affected the distribution of the mammals using presence/absence data as a function of distribution. For the analysis of these kinds of nested data with a sufficiently large sample size, mixed modelling, which will ensure convergence of maximum likelihood estimates is the optimal statistical technique recommended; and as this is a binary data, a generalized linear mixed effects logistic regression model was used. $\mathrm{R}$ packages multcomp (Hothorn et al., 2008), stats (R Core Team, 2014) and lme4 (Bates et al., 2014) were used. The large grazers' resource locating distances were expected to be substantially smaller than the spatial extent of the study area, therefore spatial auto-correlation between transects was possible. However, the mixed effects logistic regression used dealt with spatial auto-correlation within and between transects (McCulloch 
et al., 2001). In all analyses for any particular mammal, the standard deviation (a measure of the variability for each random effect, in this case, transect, different sections of the Park and observations, which were added to the model) increased through the addition of a random effect. This means that other factors, possibly including hunting intensity, competition, predation, food availability, quality of food and shelter availability, which were not considered in this research also affected the distribution of each mammal. Therefore, only "transect" was added as random effect to improve the model. To arrive at a model with the best fit, different models were compared by the anova command and a model's fitness assessed by the AIC and $\mathrm{p}$-values, following the protocol described in Zuur et al. (2009).

\section{Results}

There was no collinearity among the predictors used in the final model, indicating independence in the continuous variables. Variability in the random effect, transect, was low with variance ranging from 0.48 to 0.61 and so the assumption of homogeneity was not violated. It appeared that in all cases, the same management strategies were in operation and affected the mammals' distributions the same way in all sections of the Park.

\section{Seasonal effects on the distribution of the large herbivores}

There was little and unclear pattern of seasonal effects on the distribution of the herbivores studied. The rainy and flood seasons did not significantly predict the distribution of any of the four mammals; the dry season very highly significantly predicted the distributions of roan antelope (Estimate $=-5.564 \pm 0.054$, C.I. $=$ $-5.670--5.458, \rho<0.001)$ and hartebeest (Estimate $=-5.110 \pm 0.573$, C.I. $=-6.234--3.986$, $\rho<0.001$ ); and the fire season very highly significantly predicted the distributions of roan antelope (Estimate $=0.257 \pm 0.053$; C.I. $=$ $0.154-0.360, \rho<0.001)$ and hartebeest (Estimate $=0.861 \pm 0.236$, C.I. $=0.399-1.323, \rho<$ $0.001)$. The distributions of buffalo and waterbuck could not be predicted by seasonal changes. Both roan antelope and hartebeest tended to be scarce during the dry season and common in the fire season. Habitat shrinkage in the fire season due to burning of vast area of forage contributed to make roan antelope common in the remaining unburnt habitats.

\section{Abiotic factors that predicted the distribution} of the herbivores

The distance from the nearest source of water predicted the distribution of only the hartebeest and this was significant (Estimate $=-0.164 \pm$ 0.070 , C.I. $=-0.177--0.143, \rho<0.05$ ). For every $1 \mathrm{~km}$ distance away from the nearest source of water, there was a significant decrease in the $\log$ odds of hartebeest presence by 0.164 . Altitude significantly predicted the distributions of hartebeest $(0.007 \pm 0.002$, C.I. $=0.003-0.01$, $\rho<0.001)$ and waterbuck (Estimate $=-0.004$ \pm 0.002 , C.I. $=-0.008--0.0002, \rho<0.05)$. For every $1 \mathrm{~m}$ rise in altitude, there was a significant increase in the log odds of hartebeest presence by 0.007 and for every $1 \mathrm{~m}$ rise in altitude above sea level there was a significant decrease in the log odds of waterbuck presence by 0.004 . Waterbuck tended to inhabit places in the low lands but hartebeest tended to inhabit places at highlands nearer to sources of water (Table 2). However, the distributions of buffalo and roan antelope were not predicted by source of water or altitude. 
Anthropogenic factors that predict the distribution of the herbivores

The distance away from the park's boundary predicted the distributions of buffalo, roan antelope and hartebeest significantly $($ Estimate $=$ $0.066 \pm 0.024$, C.I. $=0.018-0.114, \rho<0.01$; Estimate $=0.257 \pm 0.053$; C.I. $=0.360-0.487$; $\mathrm{p}<0.001$; and Estimate $=0.040 \pm 0.020$, C.I. $=0.002-0.079, \rho<0.05$, respectively). For every $1 \mathrm{~km}$ distance away from the Park's boundary, there was a very significant increase in the log odds of buffalo presence by 0.066 ; for every $1 \mathrm{~km}$ distance away from the park's boundary the log odds of roan antelope presence highly significantly increased by 0.257 ; and for every $1 \mathrm{~km}$ distance away from the Park's boundary, there was a significant increase in the log odds of hartebeest presence by 0.040 . Thus, the buffalo, roan antelope and hartebeest inhabited areas in the park farther away the park's boundaries than nearer (Table 2). Distance of roan antelope from the communities/farms predicted their distribution highly significantly (Estimate $=0.049 \pm$ 0.019 ; C.I. $=0.011-0.086 ; \rho<0.01$ respectively). For every $1 \mathrm{~km}$ distance away from a community/farm the log odds of roan antelope presence highly significantly increased by 0.049 . Thus the roan were distributed farther away from the communities/farms (Table 2).

TABLE 2

Large grazers and variables that predict their distributions significantly

\begin{tabular}{lcccc}
\hline Variables & Buffalo & Roan & Waterbuck & Hartebeest \\
\hline Distance from boundary & $\sqrt{ }$ & $\sqrt{ }$ & & $\sqrt{ }$ \\
Distance from Community/farm & & $\sqrt{ }$ & & \\
Distance from Water & & & & $\sqrt{ }$ \\
Altitude & & & $\sqrt{ }$ & $\sqrt{ }$ \\
\hline
\end{tabular}

\section{Discussion}

According to Parker et al. (2009) the requirements of herbivores, including abiotic resources, affect their distribution. In this study, the abiotic factors affected the distributions of the herbivores differently; and it appeared that the responses of the large herbivores to the effects of the abiotic and anthropogenic factors constrained their distributions in a manner consistent with Senft et al. (1987). In consequence, some areas may be unexplored for foraging (Western, 1975; Redfern et al., 2005). Water requirement is one of such influential abiotic factors. As permanent water all year round was available in only few water holes in few transects in the study area, and most water bod- ies were ephemeral, it is suggested that water scarcity could account for the unclear pattern of grazers' distribution in this study. For example, waterbuck tended to inhabit places in the low lands and according to Kingdon et al. (2013) they inhabit areas near permanent sources of water but in this study the waterbuck's distribution was not predicted by sources of water. Therefore, it appeared that waterbuck inhabited lowlands to be near to sources of water. The notion by field staff (pers. com.) that waterbuck inhabited wet areas in the floodplains could not be substantiated as this study located them frequently in areas of dry ground, which is consistent with the observation by Estes (1991). The absence of water in most of the areas of 
the park in the long dry and fire seasons was a serious limiting factor that obscured the true effect of it on the distribution of the herbivores, though for the waterbuck, there was no effect of the season on their distribution. The fact that hartebeest inhabited highlands near water bodies suggested that they avoided wet grounds such as the floodplains and it is consistent with the observation by Kingdon et al. (2013) that hartebeest relocate arid habitats after rains. These may explain why the rainy and flood seasons did not affect their distribution. Buffalo and roan antelope also avoided the floodplains by selecting both lowlands and highlands. Kingdon et al. (2013) reported that roan antelope inhabited areas close to source of water, though in this study neither source of water, rainy or flood seasons predicted their distribution. Rather, the dry and fire seasons appeared important predictors for their distribution. In the fire season, it is envisaged that most grasses were burnt and so the herbivores tended to be common in the remaining unburnt habitats. It has been suggested that resource constraints during fire regimes and post-fire resource availability affect the distributions of the herbivores (Langevelde et al., 2003). In this study, the herbivores were common in the fire season but scarce in the post-fire season, perhaps, due to post-fire forage regrowth during the rainy season, which made forage abundant. Until strict control of fire regimes become part of management agenda, fire will continue to present herbivores problems with distribution at MNP. It appeared that the large grazers most sensitive to anthropogenic-induced theats were the buffalo, roan antelope and hartebeest, which were absent from areas close to the Park's boundaries or the communities. Nearly all the habitat types occurred more extensively near the boundaries of the Park, yet these herbivores were rather distributed far away from the boundaries. This suggested some form of pressure inimical to these large-bodied herbivores occurred around the communities and the Park's boundaries, which affected their distribution. Herbivores under high hunting pressure often avoid areas close to human access points, such as communities and farms near the Park's boundaries as observed elsewhere (Laurance et al., 2006; Webb et al., 2011). In general, these factors, namely, fire, water availability and anthropogenic-induced factors emerged as important factors limiting the distribution of the large herbivores, which undermined their effective conservation. Water development as a management practice has been used successfully to improve grazing distribution elsewhere (Valentine, 1947). At MNP, water is available only in two water holes in the dry and fire seasons and until water becomes seasonally and spatially available to the large grazers at MNP, it will remain impossible to see the importance of other abiotic and biotic factors to their distribution. How proximity to water resources affects the availability of other resources differs with species and landscapes (Redfern et al. 2005). For example, in this study, hartebeest needed to be close to water sources and yet they lived at highlands rather than lowlands. Also, buffalo typically would drink every 1-2 days (Estes, 1991) but they move far from water sources due to their preference to other resources (Estes, 1991) or because they must avoid areas of human presence as revealed by this study. Therefore, this study supports the hypothesis of limiting factors, mainly fire, water and anthropogenic factors, imposing constraints on the distribution of large grazers. While all these factors accounted for the lack of clear patterns of large grazer distribution, water and anthropogenic factors further made forage availability unexplored by the large grazers at MNP in most seasons. 
In conclusion, despite some limitations of the study, it successfully unraveled some important areas of the ecology of the large grazers that need to be considered in the formulation of a management plan for the effective conservation of the large grazers at MNP. Though some biotic factors such as forage quality and quantity, the extent of habitat richness and its suitability can determine the distribution of biological populations (Fahig, 2003), factors such as fire, scarcity of water and anthropogenic impacts, can also have large impacts on their distribution. Therefore, for wildlife distribution to be a necessary measure for effective species conservation, it is very important for management to ensure that there is an optimal environment almost entirely free of constraints. This tends to construct the distribution patterns that will properly define the behaviour of the large grazers on the MNP landscape. It is therefore recommended for management to address the herbivores' distribution problems identified in this study, for their effective conservation.

\section{Acknowledgments}

I am grateful to the Commonwealth Scholarship Commission, Association of Commonwealth Universities, University of Bristol and University of Cape Coast for sponsoring this research. I am also grateful to IdeaWild, Colorado, US for the supply of equipment; Professors Stephen Harris and Innes Cameron Cuthill both of the University of Bristol for consultation; Park Management and staff of Mole National Park, Mr Kwaku Frimpong and other volunteers who helped in the data collection.

\section{References}

Aikins, T. K., Gbogbo, F. \& Owusu, E. H. (2018) An evaluation of the level of human disturbance to waterbirds at Mole National Park in Ghana.
Wetlands Ecology and Management 26 (4), 703 - 713 .

Bailey, D. W., Gross, J. E., Laca, E. A., Rittenhouse, L. R., Coughenour, M. B., Swift, D.M. \& Sim, P. L. (1996) Mechanisms that result in large herbivore grazing distribution patterns. Journal of Range Management 49, 386 - 400.

Bates, D., Maechler, M., Bolker, B. \& Walker, S. (2014) _lme4: Linear mixed-effects models using Eigen and S4_.R package version 1.1-7. Retrieved from http://CRAN.R- project.org/ package $=$ lme $4>$.

Bauer, H., De Iongh, H. \& Sogbohossou, E. (2010) Assessment and mitigation of human-lion conflict in West and Central Africa. Mammalia 74, $363-367$.

Burton, A. C., Buedi, E. B., BalangtaA, C., Kpelle, D. G., Sam, M. K. \& Brashares, J. S. (2010) The decline of lions in Ghana's Mole National Park. African Journal of Ecology 49, 122 - 126.

DAKWA, K. B. (2016a) How does the cost of raid influence tolerance and support of local communities for a wildlife reserve? International Journal of Biodiversity and Conservation 8 (4), $81-92$.

DAKWA, K. B. (2016b) Allometry in sympatric grazers: Does it influence their abundance, distribution and resource selection and use patterns in the Mole National Park? Journal of Biology and Nature 5 (4), 177-184.

Estes, R. D. (1991) The behaviour guide to African mammals. Berkeley, USA: The University of California Press.

FAHIG, L. (2003) Effects of habitat fragmentation on biodiversity. Annual Review of Ecology, Evolution, and Systematics 34, 487 - 515.

Groom, R. \& Harris, S. (2010) Factors affecting the distribution patterns of zebra and wildebeest in a resource-stressed environment. African Journal of Ecology 48 (1), 159 - 168. 
Hothorn, T., Bretz, F. \& Westfall, P. (2008) Simultaneous Inference in General Parametric Models. Biometrical Journal 50, 346 - 363.

Kingdon, J., Happold, D., Butynski, T., Hoffmann, M., Happold, M., \& Kalina, J. (2013) Mammals of Africa, 6 Vols. London, England: Bloomsbury Publishing.

Langevelde, F. V., Van De Vijver, C. A. D. M., Kumar, L., Van De Koppel, J., De Ridder N., Van Andel, J., Skidmore, A. K., Hearne J. W., Stroosnijder, L., Bond, W. J., Prins, H. H. T. \& RietKerK M. (2003) Effects of fire and herbivory on the stability of savanna ecosystems. Ecology 84, 337 - 350 .

Laurance, W.F., Croes, B.M., Tchignoumba, L., Lahm, S. A., Alonso, A., Lee, M.e., Campbell P., \& OndzeAno, C. (2006) Impacts of roads and hunting on central African rainforest mammals. Conservation Biology 20, 1251 - 1261.

Mcculloch, C. E., Searle, S. R., \& Neuhaus, J. M. (2001) Generalized, Linear and Mixed Models. New York, NY: Wiley.

Parker K. L., Barboza P. S., \& Gillingham M. P. (2009) Nutrition integrates environmental responses of ungulates. Functional Ecology 23, $57-69$.

R Development Core Team (2014) R: A language and environment for statistical computing. Vienna, Austria: R-Foundation.

Redfern, J. V., Grant, C. C., Gaylard, A. \& Getz, W. M. (2005) Surface water availability and the management of herbivore distributions in an African savanna ecosystem. Journal of Arid Environments 63, 406 - 424.
Schmitt, K. \& Adu-Nsiah M. (1993) The Vegetation of Mole National Park. (Forest Resource Management Project Report No. 14). Accra, Ghana: Wildlife Division.

Senft, R. L., Coughenour, M. B., Bailey, D. W., Rittenhouse, L. R., Sala, O. E. \& Swift, D. M. (1987) Large herbivore foraging and ecological hierarchies. Bioscience 37, 789 - 795.

Valentine, K. A. (1947) Distance from water as a factor in grazing capacity of rangeland. Journal of Forestry 45 (10), 749 - 754.

Webb, S. L., Dzialak, M. R., Harju, S. M., HaydenWing, L. D. \& Winstead, J. B. (2011) Influence of land development on home range use dynamics of female elk. Wildife Research 38, $163-167$.

Western, D. (1975) Water availability and its influence on the structure and dynamics of a savanna large mammal community. African Journal of Ecology 13, 265 - 286.

Wildlife Division (2011) The Management Plan of Mole National Park. Accra, Ghana: Wildlife Division Support Project.

Wilson, V., Kpelle, D. \& Agyare, A. (1993) A Zoological Survey of Mole National Park. Accra, Ghana: International Union for the Conservation of Nature.

Zuur, A., Ieno, E. N., Walker, N., Saveliev, A. A. \& Sмith, G. M. (2009) Mixed effects models and extensions in ecology with R. New York, NY: Springer.

Received 6 Jul 18; revised 9 Oct 18. 